\title{
Yokohama Pidgin JaPaneSe ReVisited
}

\author{
Andrei A. AVRAM \\ University of Bucharest \\ andrei2.avram@gmail.com
}

\begin{abstract}
The paper is an overview of the structural features of the phonology, morphology, syntax and vocabulary of Yokohama Pidgin Japanese, an under researched contact language. The data examined are from a corpus which includes records not analyzed in previous work on this $19^{\text {th }}$ century variety of pidginized Japanese.
\end{abstract}

Keywords: Yokohama Pidgin Japanese; phonology; morphology; syntax; vocabulary

\section{Povzetek}

Članek poda pregled strukturnih značilnosti fonologije, morfologije, skladnje in besedišča v Yokohama pidžin japonščini, ki je v dosedanjih raziskavah premalo zastopan sporazumevalni jezik. Podatki za raziskavo so zajeti iz korpusa, ki vsebuje dosedaj neanalizirane zapise o tej vrsti japonščine iz devetnajstega stoletja.

Ključne besede: jokohamska pidžin japonščina; fonologija; morfologija; skladnja; besedišče

\section{Introduction}

Yokohama Pidgin Japanese (henceforth YPJ) is a variety of pidginized Japanese, spoken in the second half of the $19^{\text {th }}$ century in the multilingual setting of Yokohama ${ }^{1}$ (Daniels, 1948, pp. 805-806; Holm, 1989, p. 593; Loveday, 1996, p. 69; Inoue, 2003; Stanlaw 2004, pp. 56-59; Stanlaw 2006, p. 181; Inoue 2004, p. 116; Inoue 2006, pp. 55-56). The YPJ speech community consisted of Japanese, Westerners (Europeans and Americans), and a sizable number of Chinese (Stanlaw 2004, p. 57; Inoue 2004, pp. 116-117; Inoue, 2006, p. 56).

As is well known, pidgins can be classified according to social criteria. Sebba (1997, pp. 26-33) proposes the following classification according to the social context of the pidgin's origins: (i) military and police pidgins; (ii) seafaring and trade pidgins;

${ }^{1}$ And, most probably, in two other ports, Kobe and Nagasaki.

Acta Linguistica Asiatica, 4(2), 2014.

ISSN: 2232-3317, http://revije.ff.uni-lj.si/ala/

DOI: 10.4312/ala.4.2.67-84 
(iii) plantation pidgins; (iv) mine and construction pidgins; (v) immigrants' pidgins; (vi) tourist pidgins); (vii) urban contact vernaculars. YPJ emerged as a trade pidgin, therefore, it is assigned to type (ii). In terms of the social situation in which pidgins are used (Bakker, 1995, pp. 27-28), pidgins can be classified as follows: (i) maritime pidgins; (ii) trade pidgins; (iii) interethnic contact languages; (iv) work force pidgins. YPJ is a trade pidgin, i.e. it is a representative of type (ii).

YPJ is rather poorly documented in the literature on pidgin and creole languages. Previous descriptions of YPJ have looked at the sources of its lexicon (Daniels 1948) and a limited number of mainly morpho-syntactic features (Inoue 2003, 2004, 2006). Moreover, the analysis of YPJ by Inoue $(2003,2004,2006)$ is exclusively based on data from a single textual source, namely Atkinson (1879).

The present paper is an attempt at providing a more comprehensive overview of YPJ. The data analyzed are from a corpus consisting of the following textual sources: a phrasebook (Atkinson 1879), a glossary (Gills 1886), a dictionary (Lentzner 1892), travel accounts (Griffis 1883, Knollys 1887), and two magazine articles (Anon. ${ }^{23} 1879$ and Diósy 1879). The findings are discussed with reference to other pidgins which exhibit similar characteristics.

All examples appear in the original orthography or system of transcription. The sources are mentioned between brackets. Unless otherwise specified, the translations are from the original sources. Abbreviations used: $\mathrm{ACC}=$ accusative; $\mathrm{ADJ}=$ adjective; $\mathrm{ADV}=$ adverb; $\mathrm{D}=$ Dutch; $\mathrm{DEM}=$ demonstrative $; \mathrm{E}=$ English $\mathrm{J}=\mathrm{Japanese} ; \mathrm{N}=$ noun; $\mathrm{NEG}=$ negator $\mathrm{O}=$ object $\mathrm{P}=$ Portuguese $; \mathrm{QUANT}=$ quantifier $\mathrm{S}=$ subject $; \mathrm{SG}=$ singular; $\mathrm{V}=$ verb.

The paper is structured as follows. In section 2 I discuss the authenticity of the textual evidence. Section 3 is concerned with the phonology of YPJ. Sections 4 focuses on its morphology and syntax. In section 5 I examine the major characteristics of the vocabulary. The developmental stage attained by YPJ is discussed in section 6 . The findings are summarized in section 7 .

\section{Authenticity of textual evidence}

Given that the existence of YPJ is a matter of some debate in the literature, it is worth addressing the issue of the authenticity of the textual evidence examined.

Firstly, YPJ is mentioned by a number of contemporary authors. Diósy $(1879, \mathrm{p}$. 500) refers to it as "Yokohama dialect". The same designation is used by Griffis (1883, p. 493) ${ }^{3}$. Other authors offer additional details. Gills (1886: 185), for instance,

\footnotetext{
${ }^{2}$ According to Daniels (1948, p. 806), the author is probably C. G. Leland.

${ }^{3}$ Who erroneously believes it to be "Pigeon-English", i.e. Pidgin English (Griffis, 1883, p. 352, n.).
} 
describes it as "a species of hybrid, ungrammatical Japanese, spoken by foreigners who do not learn the language [= Japanese] accurately". Lange (1903, p. XXVIII) draws the attention of his readers to the fact that "in the ports there is a good deal of pidginJapanese (Yokohama dialect), which is to be avoided". Finally, Chamberlain (1904, p. 369) states that "in Japan [...] we have "Pidgin Japanese" as the patois in which newcomers soon learn to make known their wants to coolies and tea-house girl, and which serves as the vehicle for grave commercial transactions at the open ports". Notice that at least one author, Chamberlain (1904, p. 369), correctly recognizes the pidgin nature of YPJ.

Secondly, YPJ exhibits word-internal [y], a characteristic of earlier Tokyo Japanese:

(1) nang eye 'long' (Atkinson, 1879, p. 18) /

nangeye 'tall' (Atkinson, 1879, p. 28) (< J nagai)

Thirdly, the transcription of YPJ forms reflects devoicing of /i/ and / $\mathrm{m} /$, as well as substitution of [ $\left.\int\right]$ for Standard Japanese [ç], both phonological characteristics of the Tokyo dialectal area:

(2) shto 'man' (Atkinson, 1879, p. 25), cf. Tokyo J hito [كito]

Fourthly, a number of lexical items recorded in YPJ, e.g. the forms chobber chobber 'food, sustenance' (Atkinson 1879: 21) and tempo 'penny' (Atkinson 1879: $18)$, are attested in $19^{\text {th }}$ century Japanese:

(3) Chabu chabu komarimasŭ tempō danna san dōzo (Griffis, 1883, p. 358) grub be in trouble penny master please

'Please master, a penny; we are in great trouble for our grub.'

Fifthly, formally identical or similar YPJ lexical items are listed by different contemporary authors:

(4) a. bōtō (Diósy, 1879, p. 500)/

boto (Atkinson, 1879, p. 15) 'boat'

b. bum-bum-funé (Diósy, 1879, p. 501) /

boom-boom fune (Griffis, 1883, p. 30) 'man-of-war'

c. chobber chobber 'food, sustenance' (Atkinson, 1879, p. 21) /

chabu-chabu '(vulgar) gruel' (Diósy, 1879, p. 501)

d. come here (Atkinson 1879: 19), come here (Griffis, 1883, p. 451) /

komiya (Diósy, 1879, p. 500) 'dog'

e. dam your eye sto (Atkinson, 1879, p. 25) /

damyuri sto (Atkinson, 1879, p. 28) /

damuraïsu h'to (Diósy, 1879, p. 500) /

dammuraisu hito (Griffis, 1883, p. 493) 'sailor' 
f. hatoba 'solid granite pier' (Griffis, 1883, p. 349)/

'a pier, or landing-place' (Gills, 1886, p. 97) /

‘jetty’ (Knollys, 1887, p. 312)

g. matty 'wait' (Atkinson 1879) /

mate-mate 'wait a little' (Gills, 1883, p. 147)

Last but not least, lexical items attested in YPJ also occur - with an identical or similar form and meaning - in other Japanese-lexifier pidgins or in pidgins with Japanese as their substrate language. Consider the examples below, from Japanese Pidgin English (JPE), Thursday Island Aboriginal Japanese Pidgin (TIAJP), and Broome Pearling Lugger Pidgin (BPLP):

(5) a. YPJ ah me 'rain' (Atkinson 1897, p. 23),

TIAJP ami 'rain' (Mühlhäusler and Trew, 1996, p. 392)

b. YPJ kooksan 'cook' (Atkinson, 1879, p. 23),

TIAJP kuk-san 'cook' (Mühlhäusler and Trew, 1996, p. 392)

c. YPJ kurrumboh 'gentleman of color' (Atkinson, 1879, p. 25),

TIAJP churumpu ‘black man’ (Mühlhäusler and Trew, 1996, p. 392)

d. YPJ piggy (Atkinson, 1879, p. 21) /

peke (Diósy, p. 1879, p. 501) /

peggy (Knollys, 1887, p. 312) 'go',

BPLP peke 'go' (Broome Pearling Lugger Pidgin n.d.)

e. YPJ sacky 'wine' (Atkinson, 1879, p. 21),

JPE /sake/ or /sækiy/ 'alcoholic drink' (Goodman, 1967, pp. 51-52),

BPLP saki 'grog (in general)' (Hosokawa, 1987, p. 292),

TIAJP sagi ‘any drink' (Mühlhäusler and Trew, 1996, p. 392)

Such lexical items appear, then, to have been part of the vocabulary of the pidgins in the formation of which Japanese has been involved, be it as a lexifier or as a substrate language.

\section{Phonology}

Given the inconsistency in the orthography or system of transcription used in the currently available sources, the phonological interpretation of the written records of YPJ can only be rather tentative in nature. Nonetheless, a number of remarks can be made with respect to the phonology of YPJ.

Consider first the deletion of the high vowels /i/ and / $\mathrm{m} /$ in items etymologically derived from Japanese, which reflects their devoicing in the Tokyo-Yokohama dialectal area. As is well known, when devoiced, /i/ and / $\mathrm{w} /$ are phonetically realized as [i] and $\left[\mathrm{i}_{0}\right]$ respectively. Devoicing occurs in the following phonological environments: when the high vowel /i/ or / $\mathrm{m} /$ occurs between voiceless consonants, and in word-final position (see e.g. Author, 2005, pp. 28-33). These are also the 
environments in which deletion of $/ \mathrm{i} /$ or $/ \mathrm{m} / \mathrm{is}$ attested in YPJ forms. In the examples below, deletion is indicated by the absence of the vowel letter $\langle i\rangle$ or $\langle u\rangle$ or by the use of the apostrophe:

(6) a. arimas 'to have' (Atkinson, 1879, p. 16) < J arimasu 'to be'

b. h'to 'person' (Diósy, 1879, p. 500) < J hito 'person'

c. moots 'six' (Atkinson, 1879, p. 18) < J mutsu 'six'

d. tacksan 'much' (Atkinson, 1879, p. 18) < J takusan 'much, many'

e. watarkshee 'I' (Atkinson, 1879, p. 15) < J watakushi 'I'

As already mentioned, another phonological characteristic of the TokyoYokohama dialectal area reflected by YPJ forms (see also Daniels, 1948, pp. 810 and 813; Inoue, 2006, p. 58) is the substitution of [S] for Standard Japanese [ç]:

(7) a. shto 'man' (Atkinson, 1879, p. 20) < J hito 'person'

b. sheebatchey 'stove' (Atkinson, 1879, p. 24, f.n.) < J hibachi 'stove'

As shown above, YPJ also has word-internal [y], yet another phonological characteristic of earlier Tokyo Japanese ${ }^{4}$. Consider the following examples, in which $[\mathrm{n}]$ is rendered by the digraph $<\mathrm{ng}>$ :

(8) a. koongee 'nail' (Atkinson, 1879, p. 28) < J kugi 'nail'

b. tomango 'egg' (Atkinson, 1879, p. 24) < J tamago 'egg'

c. usangi uma 'donkey' (Diósy, 1879, p. 501) < J usagi 'hare', uma 'horse'

Inoue (2006, p. 58) claims that YPJ "generally retained the CV syllabic structure of Japanese". A more accurate and complete description would be that, generally, the syllable structure of YPJ is that of Japanese, i.e. with simple syllable margins, and with /N/ as the only consonant allowed to occur in word-final codas. As in Japanese, a consequence of the rather simple nature of the syllable structure is the substantial phonological adjustment undergone by loanwords. YPJ resorts to two repair strategies for the resolution of illicit onset and codas: epenthesis and paragoge. The former is illustrated by the examples under (4), and the latter by those under (5) below:

(9) a. bidoro 'glass' (Diósy, 1879, p. 500) < P vidro

b. buranket 'blanket' (Diósy, 1879, p. 500) < E blanket

c. sitésh'n 'railway station' (Diósy, 1879, p. 500) < E station

\footnotetext{
${ }^{4}$ See e.g. Shibatani (1990, pp. 171-173), Author (2005, pp. 48-56).
} 
(10) a. bricky 'sheet tin' (Diósy, 1879, p. 501) < D blik

b. dontaku 'Sunday' (Diósy, 1879, p. 500) < D Zondag

c. madorosu 'sailor' (Diósy, 1879, p. 501) < D matroos

The phonology of YPJ appears to have displayed considerable inter-speaker variation. This is sometimes explicitly mentioned, in the case of particular lexical items. For instance, Atkinson (1879, p. 24, f.n.) notes with respect to the word for 'stove' that "“Sheebatchey" is used as well as "Heebatchey", i.e. that the use of either [S] or presumably [ç] is attested. Other instances of variation are attributed to the different first languages of YPJ users. In his comments on the differences between the pronunciation of Westerners and that of the Chinese users of YPJ in the phonetic realization of [ $\mathrm{f}]$, Atkinson $(1879$, p. 29) writes that "foreigners as a rule rattle their "Rs" roughly, readily [...] or else ignore them altogether", whereas a Chinese "lubricates the "R"", and provides the examples reproduced below:

(11) a. Westerner walk-karrymasing / walk-kawymasing vs.

Chinese walk-kallimasing 'misunderstand (Atkinson, 1879, p. 28)

b. Westerner am buy worry vs.

Chinese am buy wolly 'not feeling well' (Atkinson, 1879, p. 28)

There is also variation in the form of the same YPJ lexical items recorded in different sources:

(12) a. piggy (Atkinson, 1879, p. 21) /

peke (Diósy, 1879, p. 501) /

peggy (Knollys, 1887, p. 312) 'go'

b. pumgutz 'punishment' (Atkinson, 1879, p. 28) /

bonkotz. 'thrashing' (Diósy, 1879, p. 501)

Finally, different variants are sometimes listed by the same author:

(13) a. jiggy jiggy / jiki jiki 'make haste' Gills (1886, p. 113)

b. maro-maro / maru-maru 'to be somewhere' (Diósy, 1879, p. 501)

\section{Morphology and syntax}

As shown by Inoue (2006, p. 60), "YPJ data do not show evidence of bound morphology". The negator nigh < $\mathrm{J}$ nai is referred as a "termination" by (Atkinson, 1879 , p. 17), but it is, in fact, a free morpheme. The only apparent exception is the negator - en < J -en, recorded in two YPJ forms: arimasen 'not to have' and walkarimasen 'not to understand'. However, these instances both involve high-frequency verbs and should, therefore, be regarded as unanalyzed forms. 
The derivational morphology of YPJ relies on the use of several word-formation means. The most frequently used one appears to have been compounding, illustrated in the following examples:

(14) a. chi chi amah 'foster mother' (Atkinson, 1879, p. 25)

b. mar gin ricky-pshaw 'two-wheeled pony carriage' (Atkinson, 1879, p. 23)

c. nammai kammy 'card' (Atkinson, 1879, p. 21)

d. niwa-tori 'rooster' (Diósy, 1879, p. 501)

e. yama-inu 'wolf' (Diósy, 1879, p. 501)

In several compounds the second member is a reflex of Japanese hito 'person':

(15) a. ah kye kimmono sto 'soldier' (Atkinson, 1879, p. 25)

b. selly shto 'auctioneer' (Atkinson, 1879, p. 25)

c. yakkamash' shto 'ambassador' (Atkinson, 1879, p. 24)

Such compounds, however, occur far less often than claimed by Inoue (2006: 60), who writes that "there is one frequently observed compounding strategy with sto/shto 'person"'. In still other compounds the second member is mono (< Japanese mono 'thing, object'):

(16) a. ato mono 'crupper' (Atkinson, 1879, p. 25)

b. caberra mono 'hat' (Atkinson, 1879, p. 15)

c. shiroy mono 'starch' (Atkinson, 1879, p. 24)

Suffixation is limited to the use of -san:

(17) a. babysan 'child' (Atkinson, 1879, p. 19)

b. doctorsan 'doctor' (Atkinson, 1879, p. 24)

c. eejin san 'foreigner' (Atkinson, 1879, p. 25)

d. kooksan 'cook' (Atkinson, 1879, p. 23)

e. Nankinsan 'Chinaman' (Atkinson, 1879, p. 25)

Reduplication is also found, but it is neither productive nor frequent. The available corpus contains just two instances of reduplicated forms:

(18) a. drunky drunky 'drunk', cf. drunky 'drunk' (Atkinson, 1879, p. 28)

b. mate-mate 'wait a little' (Gills, 1883, p. 147), cf. matty 'wait' (Atkinson, 1879, p. 20) 
Furthermore, in (18a) there seems to be no demonstrable difference in meaning between the simplex and the reduplicated form. As for the other examples recorded, they are not cases of reduplication, contra Inoue (2006, p. 60), but rather "quasireduplicated" forms ${ }^{5}$, i.e. not derived from a base attested in YPJ.

(19) a. chobber chobber 'food, sustenance' (Atkinson, 1879, p. 21)

b. maro-maro / maru-maru 'to be somewhere' (Diósy, 1879, p. 501)

c. minner minner 'all' (Atkinson, 1879, p. 22)

d. para para 'to boil' (Atkinson, 1879, p. 23)

e. pompom 'hammer' (Atkinson, 1979, p. 22)

f. sick-sick 'crank' (Atkinson, 1879, p. 20)

g. so so 'sew' (Atkinson, 1879, p. 21)

The lack of bound morphology and the small size of the vocabulary ${ }^{6}$ account for the occurrence of categorial multifunctionality ${ }^{7}$. YPJ words can be assigned to more than one lexical category and can therefore be analyzed as lexically underspecified. Consider the examples below:

(20) a. die job ADJ 'strong, sound, good, able' (Atkinson, 1879, p. 19), and ADV 'well' (Atkinson, 1879, p. 23)

b. jiggy jig V 'to hasten' (Atkinson, 1879, p. 17), ADV 'quickly' (Atkinson, 1879, p. 17), and ADJ 'the nearest' (Atkinson, 1879, p. 19)

c. pumgutz V 'punish' (Atkinson, 1879, p. 22), and N 'punishment' (Atkinson, 1879, p. 28)

d. sick-sick N 'illness' (Atkinson, 1879, p. 17), and ADJ 'sick, ill' (Atkinson, 1879, p. 28)

e. tacksan QUANT 'much' (Atkinson, 1879, p. 18), and ADV ‘very' (Atkinson, 1879, p. 28)

The system of pronouns and pronominal adjectives is extremely poorly developed. While personal pronouns distinguish three persons, there is no distinction in number:

$\begin{array}{ll}\text { watarkshee } & 1 \mathrm{SG} \\ \text { anatta / anatter and oh my } & 2 \mathrm{SG} \\ \text { acheera sto } & 3 \mathrm{SG}\end{array}$

\footnotetext{
${ }^{5}$ As defined by Bakker (2003, p. 40): "reduplicated forms for which single forms do not exist".

${ }^{6}$ The recorded vocabulary of YPJ (see Daniels 1948) amounts to approximately 250 words.

${ }^{7}$ In the sense of Mühlhäusler (1997, p. 137).
} 
Moreover, the only personal pronouns which are consistently used are watarkshee and $o h$ my. The only demonstrative recorded (just once) is kono:

(22) kono house

DEM house

'this house' (Atkinson, 1879, p. 26)

Only cardinal numerals are attested.

Since there are no plural markers on nouns or pronouns plurality is inferred from the context or is expressed by e.g. numerals.

(23) Tempo meats high kin arimas.

penny three see be

'I see three pence.' (Atkinson, 1879, p. 18)

The Japanese case markers (particles and postpositions) do not occur. The only exception found in the corpus is case of interference with Standard Japanese:

(24) Mado oh shimerro. (Atkinson, 1879, p. 24)

window ACC shut

'Shut the window.'

Given the absence of case markers, possession is expressed by juxtaposition of the possessor and the possessee:

(25) oh my tempo

2SG penny

'your penny' (Atkinson, 1879, p. 15)

Adjectives are well represented in the corpus of YPJ. The only degree of comparison attested is the absolute superlative, formed with num wun preceding the adjective:

(26) num wun your a shee

very good

'exceptionally nice' (Atkinson, 1879, p. 25)

In the absence of an adjective, num wan itself has the meaning 'best' and serves to form the relative superlative:

(27) num wun shto

best person

'the best of men' (Atkinson, 1879, p. 20) 
An overt copula arimasu (< Japanese arimasu) occurs both in equative and predicative structures:

(28) a. Tempo arimasu.

penny be

'This is a penny.' (Atkinson, 1879, p. 16)

b. Kooroy arimasu.

black be

'It is black.' (Atkinson, 1879, p. 19)

As also shown by Inoue (2006, p. 61), YPJ has no tense and aspect markers. This accounts for the fact that the temporal and aspectual interpretation relies on the context or on the use of time adverbials:

(29) a. meonitchi [...] tacksan so so arimasu.

tomorrow a lot sew be

'I will have plenty of work for him.' (Atkinson, 1879, p. 21)

b. Sigh oh narrow dozo bynebai moh skosh cow good bye please by and by more little buy

'Good bye, please buy [in the future] some more.' (Atkinson, 1879, p. 27)

There is one invariant negator, nigh $(<\mathrm{J}$ nai), which occurs in post-verbal position:

(30) Atsie sammy eel oh piggy nigh?

hot cold colour change NEG

'Does his color change in the various seasons?' (Atkinson, 1879, p. 19)

Only a very small number of adverbs are recorded. These include:

(31) a. bynebai 'by and bye' (Atkinson, 1879, p. 17)

b. coachy 'here' (Atkinson, 1879, p. 23)

c. meonitchi 'tomorrow' (Atkinson, 1879, p. 21)

The following quantifiers occur in YPJ:

(32) a. skoshe 'a little' (Atkinson, 1879, p. 18)

b. minner minner 'all' (Atkinson, 1879, p. 22)

c. tacksan 'much' (Atkinson, 1879, p. 18)

Most question words are monomorphemic, with the exception of the alternative form for 'who' in (33e): 
(33) a. dalley 'who' (Atkinson, 1879, p. 19)

b. doko 'where' (Atkinson, 1879, p. 19)

c. ikoorah 'how much' (Atkinson, 1879, p. 18)

d. nanny 'what' (Atkinson, 1879, p. 19)

e. nanny sto lit. 'what person', i.e. 'who' (Atkinson, 1879, p. 19)

In WH-questions question words remain in situ:

(34) a. Aboorah doko?

butter where

'Where is the butter' (Atkinson, 1879, p. 20)

b. Mar ikoorah?

horse how much

'How much is the horse?' (Atkinson, 1879, p. 18) [my translation]

As noted by Inoue (2006, p. 61) the word order in YPJ is SOV, as in Japanese. Generally, YPJ is typologically consistent. Consider the following parameters correlated with the SOV word order:

(35) a. possessor - possessee

oh my oh char

2SG tea

'your tea' (Atkinson, 1879, p. 15)

b. adjective - noun

die job sto (Atkinson, 1879, p. 19)

strong person

'a strong man'

c. demonstrative - noun

kono house (Atkinson, 1879, p. 26)

DEM house

'this house'

d. numeral - noun

Stoats sindoe skoshe matty.

one boatman a little wait

'Let one boatman wait.' (Atkinson, 1879, p. 20)

e. adverb - verb

coachy weedy

hither come

'come here' (Atkinson, 1879, p. 23) 
There are only a few exceptions:

(36) a. Tempo meats high kin arimas.

penny three see be

'I see three pence.' (Atkinson, 1879, p. 18)

b. verb - adverb

Oh my piggy jiggy jig

2SG get out quickly

'Get out quickly' (Atkinson, 1879, p. 28) [my translation]

c. Watarkshee tempo high kin nigh nang eye tokey.

1SG penny see NEG long time

'I have not seen a penny for a long time.' (Atkinson, 1879, p. 19)

Sentence coordination is achieved via parataxis:
watarkshe oki akindo, tacksan cow
1SG big merchant a lot buy
'I am an important merchant and I buy a lot' (Atkinson, 1879, p. 26)
[my translation]

YPJ has no overt complementizers. Whether YPJ has zero complementizers is difficult to ascertain, given the scarcity and quality of the available data. Consider the following examples:

(38) a. Start here hanash meonitchi maro maro tacksan so so arimasu tailor speak tomorrow pass a lot sew be 'Tell the tailor to come tomorrow and I will have plenty of work for him.' (Atkinson, 1879, p. 21)

b. Sin turkey hanash kimmono a row. laundryman speak clothes wash 'Tell the laundryman to wash the clothes.' (Atkinson, 1879, p. 24)

In spite of the translation in the original, the syntax of the sentences under (38) is open to two interpretations. The clauses following the verb hanash 'to tell' can be analyzed either as being complement clauses or as instances of direct speech, i.e. 'Tell the tailor: Come tomorrow and I will have plenty of work for you' and 'Tell the laundryman: Wash the clothes' respectively. Compare (38) with (39):

(39) sendo hanash drunky itchiboo sinjoe arimasen captain speak drunk one $b u$ give be 'The captain says: I won't give the drunkard one $b u$.' (Atkinson, 1879, p. 28) [my translation] 
Since the conjunctions and conjunctive particles of Japanese have not been preserved, YPJ also relies on mere juxtaposition in other types of subordinate clauses. Consider the examples of adverbial clauses of time (40), of reason (41), and of condition (42):

(40) Nanny sto arimasu, watarkshee arimasen?
who be 1SG be-NEG

'Who called when I was out?' (Atkinson, 1879, p. 19)

(41) a. Watarkshee am buy worry oh char parra parra.

$1 \mathrm{SG}$ ill tea boil

'Boil me some tea because I feel ill.' (Atkinson, 1879, p. 17)

[my translation]

b. Ginricky pshaw arimasen, mar motty koy!

man-power carriage be-NEG horse bring

'Bring a horse because there is no man-power carriage!'

(Atkinson, 1879, p. 28)

(42) a. Nanny sto hanash, watarkshee boto piggy.

anyone speak 1SG boat go

'Should anyone inquire say I've gone out in the boat.'

(Atkinson, 1879, p. 21)

b. Oh my pompom bobbery wa tarkshee pumgutz.

$2 \mathrm{SG}$ hammer noise $1 \mathrm{SG}$ punish

'If you make noise with the hammer, I'll punish you.'

(Atkinson, 1879, p. 22) [my translation]

c. Dye die job arimasen, itchiboo sinjoe nigh.

table good be-NEG one $b u$ give NEG

'If the table is not good, I won't give you a bu.' (Atkinson, 1879, p. 28)

[my translation]

As can be seen, the sequencing of clauses is generally subordinate clause - main clause, as in Japanese. There is only one exception:

(43) Nanny sto arimasu, watarkshee arimasen?

who be $1 \mathrm{SG}$ be-NEG

'Who called when I was out?' (Atkinson, 1879, p. 19)

However, what appears to be an exception may well be a pragmatically-motivated so-called "afterthought" construction, which is also attested in spoken Japanese. 


\section{Vocabulary}

Since the etyma of the lexical items found in YPJ have been discussed in great detail by Daniels (1948) this section focuses on other characteristics of its vocabulary.

Several lexical items are the outcome of reanalysis of morphemic boundaries:

(44) a. come here (Atkinson, 1879, p. 19) /

komiya (Diósy, 1879, p. 500) /

kumheer (Knollys, 1887, p. 311) 'dog'

$<$ E come here!

b. dam your eye sto (Atkinson, 1879, p. 25) /

damyuri sto (Atkinson, 1879, p. 28) /

damuraïsu h'to (Diósy, 1879, p. 500) /

dammuraisu hito (Griffis, 1883, p. 493) 'sailor'

$<$ E damn your eye (s), J hito 'man'

Also attested are lexical hybrids ${ }^{8}$ :

(45) a. kireen 'clean' (Atkinson, p. 1879, p. 25),

cf. E clean and $\mathrm{J}$ kirei

b. shiroy 'shirt' (Atkinson, 1879, p. 24),

cf. E shirt and J shiroy 'white'

Given the extremely reduced vocabulary of YPJ, synonyms would not be expected to occur. However, there are a few such instances. The synonyms are either from different source languages (43a) or from the same source language (43b):

(46) a. am buy worry (Atkinson, 1879, p. 17)

$<\mathrm{J}$ ambai 'condition', warui 'bad',

and sick-sick (Atkinson, p. 1879, p. 17) 'ill' < E sick

b. die job (Atkinson, 1879, p. 19)

$<\mathrm{J}$ daijobu 'fine',

and your a shee 'alright' (Atkinson, p. 1879, p. 18) < J yoroshii 'good'

Two other characteristics of the YPJ vocabulary are direct consequences of the extremely small size of its vocabulary. One is the occurrence of lexical polysemy. As shown below, lexical items exhibit semantic extension, and cover a wide range of meanings:

${ }^{8}$ Lexical items identified across languages, given their phonetic similarity (Mühlhäusler, 1997, p. 135) 
(47) a. aboorah 'butter, oil, kerosene, pomatum, grease' (Atkinson, 1879, p. 20)

b. arimasu 'to have, to obtain, to be, to arrive, to want' (Atkinson, 1879, p. 16)

c. ohio 'good morning, good day, good evening'9 (Atkinson, 1879, p. 17)

d. piggy 'to remove, take away, carry off, clear [the table], get out, remove' (Atkinson 1879: 17), 'change' (Atkinson, 1879, p. 19), 'push off' (Atkinson, p. 1879, p. 20) 'go(ne) out' (Atkinson, 1879, p. 21)

The extremely reduced vocabulary of YPJ also accounts for the use of lengthy and convoluted circumlocutions. Consider the following examples:

(48) a. consul bobbery sto (Atkinson, 1879, p. 25)

consul noise person 'lawyer'

b. coots pom pom otoko (Atkinson, 1879, p. 20)

shoe hammer man

'bootmaker'

c. fooney high-kin serampan nigh rosoko (Atkinson, 1879, p. 19) ship see break NEG candle 'light house'

d. okee abooneye pon pon (Atkinson, 1879, p. 23)

big dangerous hammer

'earthquake'

e. serampan funey high kin donnyson (Atkinson, 1879, p. 25)

broken ship see master

'marine insurance surveyor'

f. tacksan hanash bosan (Atkinson, 1879, p. 20)

a lot speak priest

'officiating priest'

\section{Developmental stage}

Pidgin languages have been assigned to various developmental stages, on the basis of linguistic criteria. This well-known typology (Mühlhäusler, 1997, pp. 5-6; Siegel, 2008, pp. 2-4) distinguishes accordingly three types of pidgin: (i) pre-pidgins ${ }^{10}$; (ii) stable pidgins; (iii) expanded pidgins ${ }^{11}$. Each of these types is characterized by a

\footnotetext{
${ }^{9} \mathrm{Cf}$. also the comment in Anon. (1879, p. 501) on the YPJ form ohayo: "Foreigners use it at all hours".

${ }^{10}$ Also called "minimal pidgins" or "jargons".

${ }^{11}$ An alternative term is "extended pidgins".
} 
specific set of phonological, morphological, syntactic and lexical diagnostic features (see Mühlhäusler, 1997, pp. 128-138). To these I have added one more diagnostic feature, productive morphological reduplication, since its occurrence correlates with the developmental stage of the variety at issue ${ }^{12}$.

Consider the diagnostic features of pre-pidgins set out in Table 1 in light of the data from YPJ, discussed in sections 3, 4 and 5 ("+" = occurrence of a feature; "-" = absence of a feature):

Table 1. Diagnostic features of pre-pidgins in YPJ

\begin{tabular}{||l|c|}
\hline Feature & YPJ \\
\hline \hline inter-speaker variation in phonology & + \\
\hline minimal personal pronoun system & + \\
\hline no copula & - \\
\hline no tense and aspect markers & + \\
\hline no/one adposition & + \\
\hline no complementizers & + \\
\hline non-productive reduplication & + \\
\hline categorial multifunctionality & + \\
\hline small size of vocabulary & + \\
\hline reanalysis of morphemic boundaries & + \\
\hline lexical hybrids & + \\
\hline lexical polysemy & + \\
\hline circumlocutions & + \\
\hline
\end{tabular}

As can be seen, with the exception of the copula, which, as shown in section 4 , is found in both equative and predicative structures, YPJ exhibits features diagnostic of pre-pidgins ${ }^{13}$.

\section{Conclusions}

YPJ is one of the outcomes of the language contacts which took place at the very beginning of modernity in Japan. Like other short-lived varieties emerging in similar circumstance, YPJ exhibits features typical of pre-pidgins. These characteristics have obtained via processes such as reduction, simplification, and the adoption by the

\footnotetext{
${ }^{12}$ As shown by Bakker (2003, p. 44), Bakker and Parkvall, 2005, p. 514), reduplication is not productive in pre-pidgins and stable pidgins.

${ }^{13}$ See also Inoue (2006, pp. 64-65), who uses a different set of criteria and reaches the conclusion that YPJ is a "restructured pidgin".
} 
groups of users with different first languages of compromise solutions, with a view to attending to the immediate, bare necessities of communication.

This overview of YPJ is a contribution to a better knowledge of Japanese-lexifier pidgins, which are generally under researched. It is also hoped that the data from YPJ are relevant to the literature on pidgins and creoles, in which Japanese-lexifier varieties have figured less prominently.

\section{References}

Anon. (1879) A new dialect; or, Yokohama Pidgin. Littell's Living Age 142 (1836), 496-500.

Atkinson, H. (1879) Revised and Enlarged Edition of Exercises in the Yokohama Dialect. Yokohama.

Bakker, P. (1995) Pidgins. In J. Arends, P. Muysken, and N. Smith (eds.), Pidgins and Creoles. An Introduction, 25-39. Amsterdam / Philadelphia: John Benjamins.

Bakker, P. (2003) The absence of reduplication in pidgins. In S. Kouwenberg (ed.), Twice as Meaningful. Reduplication in Pidgins, Creoles and Other Contact Languages, 37-46. London: Battlebridge.

Bakker, P. and Parkvall, M. (2005) Reduplication in pidgins and creoles. In Hurch, B. (ed.), Studies in Reduplication: 511-532. Berlin · New York: Mouton de Gruyter.

Broome Pearling Lugger Pidgin. n.d. en.wikipedia.org/wiki/Broome_Pearling_Lugger_Pidgin

Chamberlain, B. H. (1904) Things Japanese, Being Notes on Various Subjects Connected with Japan for the Use of Travellers and Others. London: Murray.

Daniels, F. J. (1948) The vocabulary of the Japanese ports lingo. Bulletin of the School of Oriental and African Studies XII (3-4), 805-823.

Diósy, A. (1879) Japoniana curiosissima. Littell's Living Age 142 (1836), 500-501.

Gills, H. A. (1886) A Glossary of Reference on Subjects Connected with the Far East, second edition. Hong Kong: Lane, Crawfors \& Co.; Shanghai \& Yokohama: Kelly \& Walsh; London: Bernard Quaritch.

Goodman, J. S. (1967) The development of a dialect of English-Japanese Pidgin. Anthropological Linguistics 9 (6), 43-55.

Griffis, W. E. (1883) The Mikado's Empire. New York: Harper \& Brothers.

Holm, J. (1989) Pidgins and Creoles, vol. II, Reference Survey. Cambridge: Cambridge University Press.

Hosokawa, K. (1987) Malay talk on boat: An account of Broome Pearling Lugger Pidgin. In D. C. Laycock and W. Winter (eds.), A World of Language: Papers Presented to Professor Stephen A. Wurm on his $65^{\text {th }}$ Birthday, 287-296. Canberra: Australian National University.

Inoue, A. (2003) Sociolinguistic history and linguistic features of Pidginized Japanese in Yokohama. Paper presented at the Annual Meeting of the Society for Pidgin and Creole Linguistics, January 2003, Atlanta. 
Inoue, A. (2004) Pidginized variety of Japanese in Yokohama: Can we label it a Pidgin?. In K. Ikeda \& J. Robideau (eds.), Proceedings 2003. Selected Papers from the College-Wide Conference for Students in Languages, Linguistics, and Literature, University of Hawai' $i$, Mānoa, 116-127. Mānoa: College of Languages, Linguistics and Literature, University of Hawai'i.

Inoue, A. (2006) Grammatical features of Yokohama Pidgin Japanese: Common characteristics of restricted Pidgins. In N. McGloin \& J. Mori (eds.), Japanese/Korean Linguistics 15, 5566.

Knollys, H. (1887) Sketches of Life in Japan. London: Chapman and Hall.

Lange, R. (1903) A Text-book of Colloquial Japanese. Tokyo: Kyobunkan.

Lentzner, K. (1892) Dictionary of the Slang English of Australia and of Some Mixed Languages: With an Appendix. Halle, Leipzig: Ehrhardt Karras.

Loveday, L. J. (1996) Language Contact in Japan. A Socio-linguistic History. Oxford: Clarendon Press.

Mühlhäusler, P. (1997) Pidgin and Creole Linguistics, expanded and revised edition. London: University of Westminster Press.

Mühlhäusler, P. and Trew, R. (1996) Japanese language in the Pacific. In S. A. Wurm, P. Mühlhäusler and D. T. Tryon (eds.), Atlas of Languages of Intercultural Communication in the Pacific, Asia, and the Americas, vol. II. 1, Texts, 373-399. Berlin · New York:

Mouton de Gruyter.

Sebba, M. (1997) Contact Languages. Pidgins and Creoles. London: Macmillan.

Shibatani, M. (1990) The Languages of Japan. Cambridge: Cambridge University Press.

Stanlaw, J. (2004) Japanese English Language and Culture Contact. Hong Kong: Hong Kong University Press.

Stanlaw, J. (2006) Japanese and English. Borrowing and contact. In K. Bolton \& B. B. Kachru (eds.), World Englishes, 179-200. New York: Routledge. 